\title{
Reliability of sickness certificates in detecting potential sick leave reduction by modifying working conditions: a clinical epidemiology study
} Nils Fleten*1, Roar Johnsen ${ }^{2}$ and Bente Skipenes Østrem ${ }^{3}$

Address: ${ }^{1}$ Department of Community Medicine, University of Tromsø, Tromsø, N-9037, Norway, ${ }^{2}$ Department of Public Health and General Practice, Norwegian University of Science and Technology, Trondheim, N-7489, Norway and ${ }^{3}$ National Insurance County Office of Troms, Tromsø, N-9259, Norway

Email: Nils Fleten* - nils.fleten@ism.uit.no; Roar Johnsen - Roar.Johnsen@medisin.ntnu.no; Bente Skipenes Østrem - Bente.Skipenes.Ostrem@trygdeetaten.no

* Corresponding author

Published: 25 March 2004

BMC Public Health 2004, 4:8

This article is available from: http://www.biomedcentral.com/l47I-2458/4/8

(c) 2004 Fleten et al; licensee BioMed Central Ltd. This is an Open Access article: verbatim copying and redistribution of this article are permitted in all media for any purpose, provided this notice is preserved along with the article's original URL.
Received: 06 October 2003

Accepted: 25 March 2004

\begin{abstract}
Background: Medical sickness certificates are generally the main source for information when scrutinizing the need for aimed intervention strategies to avoid or reduce the individual and community side effects of sick leave. This study explored the value of medical sickness certificates related to daily work in Norwegian National Insurance Offices to identify sick-listed persons, where modified working conditions might reduce the ongoing sick leave.
\end{abstract}

Methods: The potential for reducing the ongoing sick leave by modifying working conditions was individually assessed on routine sickness certificates in 999 consecutive sick leave episodes by four Norwegian National Insurance collaborators, two with and two without formal medical competence. The study took place in Northern Norway in 1997 and 1998. Agreement analysed with differences against mean, kappa, and proportional-agreement analysis within and between groups of assessors was used in the judgement. Agreements between the assessors and the selfassessment of sick-listed subjects were additionally analysed in 159 sick-leave episodes.

Results: Both sick-listed subjects and National Insurance collaborators anticipated a potential reduction in sick leave in $20-30 \%$ of cases, and in another $20 \%$ the potential was assessed as possible. The chance corrected agreements, however, were poor $(k<0.20)$ within and between groups of National Insurance collaborators. The agreement between National Insurance collaborators and the sick-listed subjects was no better than chance. Neither extended medical information nor formal medical competence increased agreement in cases where modified working conditions might have reduced sick leave.

Conclusion: Information in medical sickness certificates proved ineffective in detecting cases where modified working conditions may reduce sick leave, and focusing on medical certificates may prevent identification of needed interventions. Strategies on how to communicate directly with sick-listed subjects would enable social authorities to exploit more of the sick leave reduction potential by modifying the working conditions than strategies on improving medical information. 


\section{Background}

The increasing rate of sick leave experienced in most Western European countries challenges insurance companies, employers, and public authorities to identify measures to reduce the associated burdens on individuals, workplaces, and finances. Sick-listed persons assume that modified working conditions can reduce sick leave [1,2], primary health care practitioners rank lack of light-duty availability as the most important barrier to improved return to work [3], and programmes for modifying working conditions are shown to facilitate return to work [4].

In Norway, the White Paper of Vocational Rehabilitation of 1991 focused on modifying working conditions to facilitate return to work when sick listed. Active sick leave has been offered from 1993 to promote early return to work and to encourage the use of many kinds of modifications to working conditions such as improved physical or psychosocial work factors and to provide more appropriate duties at work [5]. The Norwegian Social Insurance Scheme refunds sickness benefits when active sick leave is accepted. Early identification of sick-listed persons that might profit from many kinds of modified working conditions, including active sick leave, has become a major challenge to the Norwegian National Insurance Offices (NIOs). This identification process depends mainly on information found in sickness certificates from general practitioners (GP). In Norway a medical sickness certificate (Sickness Certificate 1, SC1) is required if the sick leave exceeds 3 days, and an extended medical certificate is required if the sick leave exceeds 8 weeks (Sickness Certificate 2, SC2) [6]. In addition to diagnosis, certified period, and extent of the sick leave, the majority of the SC1 contains information about the type of occupation and employee. Information on chronic diseases, previous sick leave episodes, prognosis, and comments is more scattered. The SC2 includes updated medical information on work ability, further diagnostic and treatment plans, and on prognosis.

This certifying process consumes considerable resources. A Norwegian study indicated that GPs spent $9 \%$ of their working hours on social security certification [7], and an audit study in Sweden found that $9 \%$ of all consultations included sick-listing considerations [8].

The majority of sick leave reduction strategies rely on the assumption that the information in Medical Certificates provides NIOs with sufficient information to identify sicklisted persons for relevant measures. However, despite the resources spent on sickness certificates, to our knowledge this assumption has not been tested according to daily practice. The objective of this study was, therefore, to explore the value of the information in the SC1 and in the more extensive SC2, to identify sick-listed persons where the ongoing sick leave could probably be reduced by specific modifications to working conditions.

\section{Methods}

The study was designed to explore agreement on the following question: Do you think that modifications to working conditions could reduce the ongoing period of sick leave, either by shortening the total duration or by initiating part-time work? The question was assessed according to daily practice on different levels of medical information and with and without formal medical competence within the NIOs (Figure 1). The protocol specified that a yes presumed eligibility for and possible sick leave reduction by modifications to working conditions. The questionnaire gave eight alternatives for these possible modifications: (1) none, (2) adjustment of work environment, (3) adjustment of work duties, (4) increased autonomies, (5) psychosocial improvements, (6) increased appreciation, (7) vocational rehabilitation, and (8) unspecified others [2].

In October-November 1997 and February-March 1998 the NIOs in the cities of Harstad (23,000 inhabitants) and Tromsø (59,000 inhabitants) included a total of 999 consecutive sick-listed persons with sick-leave periods that exceeded 2 weeks. The mean age of the 392 sick-listed men was 41.5 years (SD 12.1 years), and 39.7 years (SD 11.4 years) for the 607 women. The minimum and maximum ages were 17 and 66 years, respectively, and median male and female ages were 42 and 39 years, respectively.

The diagnostic inclusion criteria were a musculoskeletal or mental disorder, L- and P-diagnoses according to the International Classification of Primary Health Care [9]. Musculoskeletal disorders were classified as the main reason for the ongoing sickness absence in $82.9 \%$ of the included persons. A SC2 subsequently became accessible in 343 of the included sick leave episodes.

Two National Insurance medical consultants and four National Insurance officers from three NIOs were recruited to perform the assessments. Both medical consultants assessed 983 of the included sick leave forms at 14 days of sick leave, and each of the officers assessed about half of the included sick leave forms. The pairs of officers were randomly drawn for each group of ten sick leave forms.

Half of the sick leave forms $(n=501)$ selected randomly were assessed on the basis of available sickness certificates alone (Figure 1$)$. The remaining half $(n=498)$ were assessed with additional information registered from previous sick-leave episodes. The number of available sickness certificates for each sick-listed subject ranged from one $(56.5 \%)$ to four $(0.6 \%)$, with a mean of 1.5 at 14 days 


\section{Inclusions}

The National Insurance Offices in the cities of Harstad and Troms $\varnothing$ included 999 consecutive sick-listed persons exceeding 2 weeks of absence due to musculoskeletal or mental disorder during October-November 1997 and February-March 1998.

\section{Sickness Certificate 1}

Two National Insurance officers and two National Insurance medical consultants assessed individually the following question: Do you think that modifications to working conditions could reduce the ongoing period of sick leave? The following cases were randomly extracted:

a) 501 cases assessed using only Sickness Certificate 1.

b) 498 cases assessed using Sickness Certificate 1 and the history of sickness benefits.

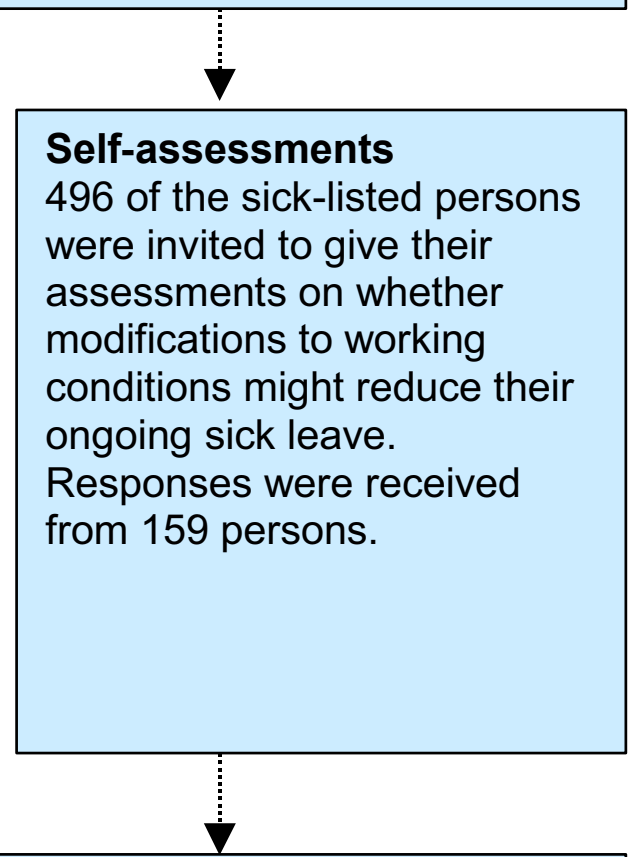

\section{Sickness Certificate 2}

The same four assessors reassessed the 343 cases where a Sickness Certificate 2 became available with access to history of sickness benefits, Sickness Certificate 1, and Sickness Certificate 2.

\section{Reproducibility study by medical consultants} Reproducibility study of 20 cases randomly extracted from cases with self-assessments and a Sickness Certificate 2:

a) Assessments based on Sickness Certificate 1, performed by ten consultants.

b) Assessments based on Sickness Certificates 1 and 2, performed by seven consultants.

c) Assessments based on Sickness Certificates 1 and 2 and the self-assessments, performed by nine consultants.

Figure I

Information levels for assessments. Flow chart showing the different assessments of whether or not modified working conditions might reduce the ongoing sick-leave episode.

of sick leave. The 343 sick leave forms with SC2s were reassessed independently from the first rating, based on all available information.
The 2-week analyses correspond to the time when the National Insurance Service becomes responsible for sickness benefits, and analyses of SC2s correspond to medical information available for a formal conclusion of sickness benefits beyond 12 weeks. 
A random selection of 496 of the included sick-listed subjects were invited to give their assessments when their sick leave passed 14 days. Completed questionnaires were returned by 161 (32.4\%) of these subjects, and 159 had assessed whether work adjustments, in general, could reduce the ongoing period of sick leave. There were no significant differences between the 159 responders and the non-responders regarding sex, age, length of sick leave episodes during the previous 3 years, and the distributions of diagnoses and occupations [2].

To analyse the reproducibility of the NIO medical consultants, 20 randomly selected cases with self-assessments and SC2s were reassessed. Another 15 physicians working part time as NIO consultants were asked to complete the same questionnaire based on the information available after 2 weeks in these 20 cases, and ten of these consultants responded (Figure 1).

Six weeks later, in a conference on the topic, seven NIO medical consultants assessed the same 20 cases, now based on all routine information available including SC2s. On the same occasion, another nine consultants performed the same assessments but including the additional knowledge of the self-assessments of sick-listed subjects.

\section{Analyses and data management}

We considered agreement between and within NIO officers and medical consultants, and agreement between sicklisted subjects and NIO collaborators, to be appropriate estimates of the ability to identify the sick-listed subjects who might reduce their ongoing sick leave period by working under modified conditions [10]. In order to attend the variance, the possibility for reduction - either by shortening the length or by starting part-time work was assessed on an 80-mm visual analogue scale (VAS), from certainly no $(0 \mathrm{~mm})$ to certainly yes $(80 \mathrm{~mm})$. Differences in assessments on the VAS between sick-listed subjects and NIO officers or medical consultants were analysed using a differences-against-mean (Bland-Altman) diagram [11].

Related to practical use, categorical agreement on whether modified working conditions could, might, or could not reduce the actual sick leave was analysed with kappa, observed agreement, and specific proportional agreement [12]. Categorisations of the VAS into yes, uncertain, and no were performed individually: each officer and consultant marked their interval for uncertain on six different VASs and gave their interpretation of ten example scales in these three categories. The mean individual upper limit of no varied from 34 to $38 \mathrm{~mm}$, and the lower limit of yes varied from 43 to $50 \mathrm{~mm}$ after this procedure. The means of these limits, together with the assessments of three other officers, were used to categorise the assessments of the sick-listed subjects.

All reproducibility assessments were performed according to these three categories. The information from questionnaires, sickness certificates, and histories of sickness benefits were registered in Epi-Info, which was used for ordinary descriptive and comparison statistics. Scatter plot and correlation analyses were performed using SPSS10. Pearson's or Spearman's correlations were used to illustrate correlation if normality assumptions were satisfied or not. The summation of the $3 \times 3$ tables and calculations of agreement with confidence intervals (CIs) of kappa [13] were performed in a Microsoft Excel model. Exact binomial 95\% CIs were used for the other agreement measures.

\section{Approval}

The Regional Ethical Committee approved the protocol, and the Norwegian Data Inspectorate licensed the necessary register of sick-listed subjects.

\section{Results}

\section{Assessments of possible sick leave reduction}

The assessments of whether modified working conditions might reduce the ongoing sick leave showed a large range in the proportion of yes results within professions (Table 1 ), with the mean proportion being higher for NIO officers than for NIO medical consultants. The Pearson's correlation between mean assessments of NIO medical consultants and officers was low $(r=0.22, p<0.001)$. Missing occupation information increased the proportion of uncertain estimates, whereas additional information from SC2s reduced the proportion of such estimates among officers $(p=0.02)$, but not among consultants $(p=$ $0.2)$.

The assessments of the sick-listed subjects exhibited a triple-clustered distribution that corresponded to the categorisation into no (50.9\%), uncertain (19.5\%), and yes (29.6\%). The mean proportion of yes assessments in this group of sick-listed subjects was $28.1 \%$ (95\% CI 21.335.8 ) for officers and $29.6 \%$ (95\% CI 22.7-37.5) for consultants. Spearman's correlation was, however, low and insignificant between assessments of sick-listed subjects and mean assessments of groups of NIO assessors. The difference-against-mean analysis revealed that the mean assessments of both NIO officers and medical consultants failed to identify the majority of the cases where the sicklisted subjects predicted effects of modified working conditions (Figure 2).

\section{Inter- and intra-observer agreement}

The inter-observer agreements of whether modified working conditions might reduce the ongoing sick leave were 
Table I: Assessments of potential sick leave reduction by modifications to working conditions.

\begin{tabular}{|c|c|c|c|c|c|c|c|c|c|}
\hline \multirow[b]{2}{*}{ Assessment based on- } & \multirow[b]{2}{*}{$\begin{array}{l}\text { Number of sick } \\
\text { leave forms }\end{array}$} & \multicolumn{4}{|c|}{ Officers answers of } & \multicolumn{4}{|c|}{ Consultants answers of } \\
\hline & & $\begin{array}{l}\text { Number of } \\
\text { assessments }^{\mathrm{a}}\end{array}$ & Uncertain \% & Yes \% $(95 \% \mathrm{Cl})$ & $\begin{array}{c}\text { Yes \% } \\
\text { Minimum } \\
\text { Maximum }\end{array}$ & $\begin{array}{l}\text { Number of } \\
\text { assessments }^{\mathrm{a}}\end{array}$ & Uncertain \% & Yes \% $(95 \% \mathrm{Cl})$ & $\begin{array}{c}\text { Yes \% } \\
\text { Minimum } \\
\text { Maximum }\end{array}$ \\
\hline $\begin{array}{l}\text { Sickness Certificate I } \\
(\mathrm{SCI})\end{array}$ & 501 & 990 & 24.9 & $30.1(26.1,34.4)$ & $23.9,41.8$ & 992 & 20.2 & $22.1(18.6,26.1)$ & $8.5,35.4$ \\
\hline $\begin{array}{l}\text { SCI + additional } \\
\text { history of sick-leave }\end{array}$ & 498 & 991 & 24.4 & $30.5(26.5,34.8)$ & $19.4,43.7$ & 989 & 21.1 & $20.6(17.2,24.5)$ & $8.1,39.8$ \\
\hline $\begin{array}{l}\text { Subgroup } \mathrm{SCl}+ \\
\text { occupation not } \\
\text { notified }\end{array}$ & 221 & 436 & 35.6 & $24.5(18.9,30.6)$ & $13.8,41.2$ & 439 & 31.9 & I5.7 (| |.2, 2|.3) & $6.0,25.3$ \\
\hline $\begin{array}{l}\text { Subgroup } \mathrm{SCl}+ \\
\text { special notification } \\
\text { from the practitioner }\end{array}$ & 24 & 48 & 20.8 & $47.9(27.4,69.0)$ & $23.1,83.3$ & 48 & 16.7 & $41.7(22.1,63.4)$ & $25.0,58.3$ \\
\hline $\begin{array}{l}\text { SCI in Sickness } \\
\text { Certificate } 2 \\
\text { subgroup }\end{array}$ & 343 & 679 & 25.5 & $32.7(27.7,37.9)$ & $25.7,39.4$ & 684 & 19.2 & $25.4(20.8,30.3)$ & $12.0,38.8$ \\
\hline Sickness Certificate 2 & 343 & 680 & 17.9 & $34.6(29.6,39.9)$ & $26.2,44.3$ & 683 & 15.4 & $28.3(23.6,33.4)$ & $19.8,36.8$ \\
\hline
\end{tabular}

a Missing assessments produce inconsistencies between the number of sick-listed subjects and the number of assessments. Assessments by NIO officers and medical consultants of whether modified working conditions might reduce the ongoing sick leave based on different levels of information. Proportions of yes and uncertain results are presented as means.

low within and between the groups of NIO officers and medical consultants (Table 2). Inclusion of the SC2 increased the observed and chance-corrected agreement, but kappa was still less than 0.20 within and between groups of assessors.

The chance-corrected agreement, kappa, between the sicklisted subjects and NIO assessors was not different from zero, with one exception (Table 3 ). Within the group of seven consultants, kappa was less than zero. Inclusion of the SC2 reduced the observed and chance-corrected agreement with the sick-listed subjects.

Reproducibility tests within the two consultants showed that the intra-observer agreement was fair $(k=0.23)$, and increased to moderate $(k=0.52)$ with the inclusion of SC2 (Table 4). The inter-observer agreement between all consultants, however, never exceeded poor agreement, even with knowledge of the opinions of sick-listed subjects.

\section{Discussion}

This study explored the ability to identify sick-listed subjects for which work-related measures might reduce sick leave based on sickness certificate-mediated information from GPs, according to everyday work in Norwegian NIOs. Surprisingly, there was virtually no agreement beyond chance within or between groups of NIO officers and medical consultants about in which cases modified working conditions might contribute to reducing the ongoing sick-leave period. In addition, the chanceadjusted agreement between sick-listed subjects and officers or consultants regarding whether the sick-listed subjects could benefit from modified working conditions did not differ significantly from zero. Neither additional medical and social information nor formal medical competence improved agreement within or between groups.

\section{Methods}

The representativity of the assessors is essential in the interpretation of the result. The selection of interested and experienced officers - rather than using randomly selected officers - might give an overestimation of the officers' capacity to identify candidates for modified working conditions. Additionally, in this open study, we would expect the NIO officers and consultants to perform at least as well as they do in their regular work.

The NIO medical consultants showed a wider range in their probability assessments than did the officers, and the bias index (Table 2) indicated a systematic different attitude to the potential effect of work adjustment. Nevertheless, we did not find any significant difference in agreement between the sick-listed subjects and each of the two medical consultants, or in agreement between groups of medical consultants and the sick-listed subjects. The scores of both medical consultants were within the range of those of the ten colleagues in the reproducibility part of the study.

The low response rate among the sick-listed subjects may have introduced a selection bias, but no significant differences were found in the distributions of sex, age, diagnoses between responders and non-responders. Any selection bias would probably favour a selection of those with an unambiguous opinion on whether or not they could benefit from modified working conditions. How- 


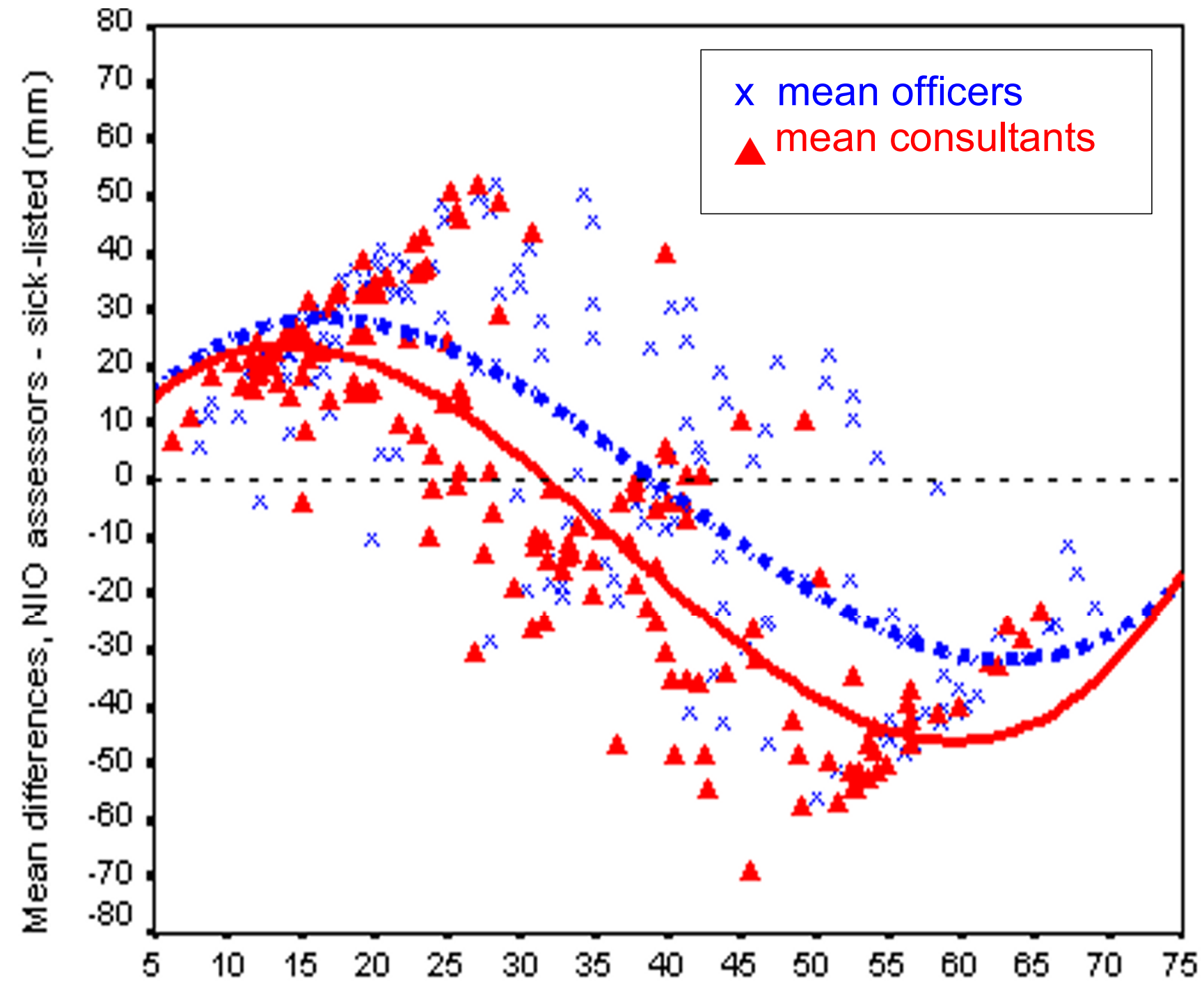

\section{Mean assessments of NO assessors and sick-listed (mm)}

\section{Figure 2}

Differences in assessed sick leave reduction potential by modifications to working conditions. Bland-Altman plot of difference between mean assessments of probable sick leave reduction potential by National Insurance officers and National Insurance medical consultants, and the sick-listed subjects plotted against mean assessments of National Insurance collaborators and sick-listed subjects $(n=157)$. The cubic regression fit lines indicate the mean differences.

ever, the agreement among NIO assessors in the responder group was no better than that in the nonresponder group. We also did not find a better agreement between NIO assessors and sick-listed subjects in the subgroup of sick-listed subjects who assessed possible benefits with an unambiguous yes $(>60 \mathrm{~mm})$ or $n o(<20 \mathrm{~mm})$ on the VAS. Taken together, these results indicate that selection bias is unlikely to explain the low agreement between the sick-listed subjects and the NIO officers and medical consultants.

A different interpretation of the VAS might also be a potential hazard to the results. The processes of individual categorisation of yes, uncertain, and no by NIO officers and 
Table 2: Agreement on potential sick leave reduction by modifications to working conditions.

\begin{tabular}{|c|c|c|c|c|c|c|c|}
\hline Observer agreement & $\begin{array}{l}\text { Number of sick } \\
\text { leave forms }\end{array}$ & $\begin{array}{c}\text { Pairs of } \\
\text { assessments }^{\mathrm{a}}\end{array}$ & Bias index (BI) & $\begin{array}{c}\text { Observed } \\
\text { agreement (Po) }\end{array}$ & Kappa & $\begin{array}{l}\text { Proportional } \\
\text { agreement yes } \\
\text { (Ppos) }\end{array}$ & $\begin{array}{l}\text { Proportional } \\
\text { agreement no } \\
\text { (Pneg) }\end{array}$ \\
\hline \multicolumn{8}{|l|}{ Within officers } \\
\hline Sickness Certificate I & 999 & 985 & 0.05 & $0.40(0.37,0.43)$ & $0.06(0.02,0.09)$ & $0.37(0.33,0.4 I)$ & $0.5 \mathrm{I}(0.47,0.54)$ \\
\hline Sickness Certificate 2 & 343 & 337 & 0.04 & $0.49(0.44,0.55)$ & $0.19(0.10,0.27)$ & $0.45(0.38,0.5 \mathrm{I})$ & $0.63(0.57,0.68)$ \\
\hline \multicolumn{8}{|l|}{$\begin{array}{l}\text { Within } \\
\text { consultants }\end{array}$} \\
\hline Sickness Certificate I & 999 & 983 & 0.39 & $0.4 I(0.38,0.44)$ & $0.05(0.00,0.10)$ & $0.16(0.13,0.20)$ & $0.54(0.52,0.57)$ \\
\hline Sickness Certificate 2 & 343 & 340 & 0.32 & $0.49(0.43,0.54)$ & $0.17(0.08,0.25)$ & $0.42(0.35,0.49)$ & $0.61(0.56,0.66)$ \\
\hline \multicolumn{8}{|l|}{$\begin{array}{l}\text { Between officers } \\
\text { and consultants }\end{array}$} \\
\hline $\begin{array}{l}\text { Sickness Certificate I } \\
\text { - historical sick leaves }\end{array}$ & 501 & 2947 & 0.16 & $0.42(0.40,0.44)$ & $0.08(0.05,0.11)$ & $0.31(0.29,0.33)$ & $0.54(0.52,0.56)$ \\
\hline $\begin{array}{l}\text { Sickness Certificate I } \\
+ \text { historical sick } \\
\text { leaves }\end{array}$ & 498 & 2953 & 0.16 & $0.42(0.40,0.43)$ & $0.07(0.04,0.09)$ & $0.29(0.26,0.31)$ & $0.55(0.53,0.56)$ \\
\hline Sickness Certificate 2 & 343 & 2031 & 0.10 & $0.48(0.46,0.5 \mathrm{I})$ & $0.15(0.12,0.19)$ & $0.43(0.40,0.45)$ & $0.61(0.59,0.63)$ \\
\hline
\end{tabular}

a Missing assessments produce inconsistencies between the number of sick-listed subjects and the number of pairs of assessments. Observer agreement on whether work adjustments might reduce the ongoing sick leave assessed in the categories of yes, uncertain, and no, within and between National Insurance officers and consultants, regarding different levels of information. $95 \%$ confidence intervals (Cls) are given in brackets.

Table 3: Agreement between sick-listed subjects and National Insurance assessors.

\begin{tabular}{|c|c|c|c|c|c|c|c|}
\hline $\begin{array}{l}\text { Observed agreement } \\
\text { between sick-listed } \\
\text { and }\end{array}$ & $\begin{array}{l}\text { Number of } \\
\text { sick-listed }\end{array}$ & $\begin{array}{c}\text { Pairs of } \\
\text { assessments }^{\mathrm{a}}\end{array}$ & Bias index (BI) & $\begin{array}{c}\text { Observed } \\
\text { agreement (Po) }\end{array}$ & Kappa & $\begin{array}{l}\text { Proportional } \\
\text { agreement yes } \\
\text { (Ppos) }\end{array}$ & $\begin{array}{l}\text { Proportional } \\
\text { agreement no } \\
\text { (Pneg) }\end{array}$ \\
\hline \multicolumn{8}{|l|}{-Officers } \\
\hline Sickness Certificate I & 159 & 317 & 0.09 & $0.38(0.33,0.43)$ & $0.05(-0.03,0.13)$ & $0.34(0.27,0.4 I)$ & $0.49(0.43,0.55)$ \\
\hline Sickness Certificate 2 & 60 & 120 & 0.08 & $0.33(0.24,0.42)$ & $-0.05(-0.18,0.08)$ & $0.23(0.15,0.33)$ & $0.44(0.33,0.54)$ \\
\hline \multicolumn{8}{|l|}{$\begin{array}{l}\text {-Medical } \\
\text { consultants }\end{array}$} \\
\hline Sickness Certificate I & 159 & 316 & 0.01 & $0.39(0.33,0.44)$ & $-0.01(-0.10,0.08)$ & $0.28(0.21,0.35)$ & $0.52(0.47,0.58)$ \\
\hline Sickness Certificate 2 & 60 & 119 & 0.05 & $0.36(0.28,0.45)$ & $-0.05(-0.19,0.09)$ & $0.23(0.14,0.34)$ & $0.48(0.39,0.57)$ \\
\hline \multicolumn{8}{|l|}{$\begin{array}{l}\text {-Extended group of } \\
\text { medical consultants }\end{array}$} \\
\hline Sickness Certificate I & 20 & 200 & 0.05 & $0.31(0.24,0.37)$ & $-0.12(-0.22,0.02)$ & $0.30(0.23,0.38)$ & $0.39(0.32,0.46)$ \\
\hline \multicolumn{8}{|l|}{ Seven consultants } \\
\hline Sickness Certificate 2 & 20 & 137 & 0.17 & $0.31(0.23,0.39)$ & $-0.18(-0.31,-0.04)$ & $0.35(0.27,0.44)$ & $0.32(0.24,0.4 \mathrm{I})$ \\
\hline
\end{tabular}

a Missing assessments produce inconsistencies between the number of sick-listed subjects and the number of pairs of assessments. Observer agreement on whether work adjustments might reduce the ongoing sick leave assessed in the categories of yes, uncertain, and no, between sick-listed subjects and National Insurance officers and consultants. $95 \% \mathrm{Cls}$ are given in brackets.

medical consultants secure their interpretation of the scale. The triple-clustered distribution of the assessments of sick-listed subjects reduces the possible influence of variation in interpretation of the scale. The subgroup analysis of those with unambiguous opinions also suggests that a different interpretation of the VAS did not influence our results.
The question asked might introduce a hierarchy, first eligibility for modified working condition, and secondly potential sick leave reduction if this was effectuated. The instructions to the assessors focused on reduced sick leave, and ambiguity of the question are probably not important to the result. 
Table 4: Reproducibility of assessed sick leave reduction.

\begin{tabular}{|c|c|c|c|c|c|c|c|}
\hline & $\begin{array}{l}\text { Number of } \\
\text { sick leave } \\
\text { forms }\end{array}$ & $\begin{array}{c}\text { Pairs of } \\
\text { assessments }\end{array}$ & $\begin{array}{l}\text { Bias Index } \\
\quad \text { (BI) }\end{array}$ & $\begin{array}{c}\text { Observed } \\
\text { agreement (Po) }\end{array}$ & Kappa & $\begin{array}{l}\text { Proportional } \\
\text { agreement yes } \\
\text { (Ppos) }\end{array}$ & $\begin{array}{l}\text { Proportional } \\
\text { agreement no } \\
\text { (Pneg) }\end{array}$ \\
\hline \multicolumn{8}{|l|}{$\begin{array}{l}\text { Intra-observer } \\
\text { agreement }\end{array}$} \\
\hline Sickness Certificate I & 20 & 40 & 0.28 & $0.53(0.36,0.68)$ & $0.23(-0.03,0.48)$ & $0.29(0.11,0.52)$ & $0.7 \mid(0.56,0.84)$ \\
\hline Sickness Certificate 2 & 20 & 40 & 0.05 & $0.75(0.59,0.87)$ & $0.52(0.26,0.78)$ & $0.77(0.56,0.91)$ & $0.82(0.67,0.91)$ \\
\hline \multicolumn{8}{|l|}{$\begin{array}{l}\text { Inter-observer } \\
\text { agreement between }\end{array}$} \\
\hline $\begin{array}{l}\text { Sickness Certificate I } \\
\text { Seven consultants }\end{array}$ & 20 & 860 & 0.08 & $0.43(0.40,0.47)$ & $0.12(0.07,0.17)$ & $0.48(0.44,0.52)$ & $0.46(0.43,0.50)$ \\
\hline $\begin{array}{l}\text { Sickness Certificate } 2 \\
\text { Nine consultants }\end{array}$ & 20 & 402 & 0.15 & $0.48(0.43,0.53)$ & $0.07(-0.02,0.16)$ & $0.59(0.55,0.64)$ & $0.39(0.33,0.45)$ \\
\hline $\begin{array}{l}\text { Sickness Certificate } 2 \\
\text { and sick-listeds' self- } \\
\text { assessment }\end{array}$ & 20 & 491 & 0.06 & $0.54(0.50,0.59)$ & $0.20(0.12,0.28)$ & $0.60(0.56,0.65)$ & $0.55(0.50,0.60)$ \\
\hline
\end{tabular}

a Missing assessments produce inconsistencies between the number of sick-listed subjects and the number of pairs of assessments. Reproducibility of the assessments of National Insurance consultants on whether work adjustments might reduce the ongoing sick leave in the categories of yes, uncertain, and no, presented as intra- and inter-observer agreement for different levels of information. $95 \% \mathrm{Cls}$ are given in brackets.

\section{Identifying sick-listed subjects who could profit from modified working conditions}

Sick-listed subjects, officers, and consultants expressed a firm belief that work adjustments would reduce sick leave, in line with results from other studies [1,14-16]. The poor agreement among and between NIO officers and medical consultants demonstrates that medical certificates include little information on factors important for predicting a potential sick-leave reduction by modified working conditions. The fact that agreement was no higher among medical consultants, with their medical competence, supports the impression that medical information is of little value to this topic. The effects of extended medical information on intra- and inter-observer agreement, however, indicate that there are some shared ideas concerning indicators that favour modified working conditions. The relevance of these ideas is questioned by the decrease in agreement with the sick-listed subjects when extended medical information was available. The time span between self-assessments and assessments based on SC2s barely influenced the result. If an effect had been found, waiting for extended medical information might obstruct the possible effect of modified working conditions more than it provides relevant information related to modifying working conditions. The modest relevance of medical information might explain the slow implementation of active sick leave [5], and why Ringdal et al could not demonstrate any effect on health insurance utilisation by a systematic evaluation of SC2s [17].

\section{Factors associated with sick leave}

The results from the present study indicate that information about symptoms, disorders, diagnosis, treatment, and the course of the illness, together with information on sex, age, and occupation have only marginal impact on the sick leave-reducing potential of modifying the working conditions, according to the sick-listed subjects themselves. Sick leave might be seen as a product of a reduced work ability depending on a combination of social and medical conditions and the work demands, where sickness certificates primarily legitimate disease as the cause of incapacity to work. Practitioners are traditionally focused on treating disease, and their insight into the facets of individual work demands and abilities may be no better than that of laypeople.

When initial sickness certification is shown to be predominantly patient-controlled, this can be interpreted as an acceptance of the patient as the expert $[8,18]$ in weighing individual work capacity against work demand. These considerations will be influenced by several factors, since possibilities for replacement [14], attitudes towards pain [19], and psychosocial work environment $[16,20]$ might explain why improving work conditions is important in a successful rehabilitation to work [21]. In this context information of sickness will be a necessary, but not a sufficient explanation of sick leave episodes, and such information cannot replace asking the sick-listed subjects whether modified working conditions might be appropriate in their case. 


\section{Might medical certificates obstruct the determination of useful modifications to working conditions?}

The absence of a common understanding of which type of information in medical certificates can help predict a potential effect of modified working conditions suggests that the opinions of sick-listed subjects are the most accurate. The differences against mean analyses and the low agreement between medical consultants that have knowledge about the self-assessments of sick-listed subjects indicate that judgements by medical expertise may obstruct possible modified working conditions. This view is supported by the findings of Reiso et al. [22], who demonstrated that among 266 newly sick-listed patients, GPs assessed work ability as much or very much reduced in 23 out of 29 patients who assessed their own work ability as not much or hardly reduced at all.

If a positive attitude to modified working conditions among sick-listed subjects is a prerequisite for success, efforts to select early interventions based on medical certificates is primarily a waste of resources. Further, it disqualifies two-thirds of the sick-listed subjects that potentially may profit from such intervention.

Considering the amount of attention devoted to the potential of sick-leave-reduction measures in Western Europe, there is a notable lack of studies focusing on how to identify the individual sick-listed persons who might profit from modified working conditions. Our findings question any intervention programme guided by medical certificates that does not also consider the opinions of sick-listed persons on working conditions, possibilities, and capacity. Our results support a focus shift from medical certification to dialogue between employee and employer in order to reap the benefits from modified working conditions, and studies with this focus should be carried out.

\section{Conclusions}

According to ordinary practice the information within medical sickness certificates proved insufficient for detecting potential sick leave reduction by modifications to working conditions. Neither extended medical information nor formal medical competence increased the ability to identify potential effects of modified working conditions. Furthermore, the majority of sick-listed persons expecting a reduced sick leave following modifications to their working conditions would be missed when the selections were based on medical sickness certificates alone. Therefore, strategies for direct communication with sicklisted persons would most probably improve the ability of social authorities to reduce sick leave by modifying working conditions more than strategies for improving medical information.

\section{Competing interests}

The authors N.F. and B.S. $\varnothing$ are both part-time employed as National Insurance medical consultants.

\section{Authors' contributions}

N.F. was in charge of designing and running the study, and performed most of the analyses and the writing of this manuscript. R.J. actively supervised all parts of the study, and B.S.Ø. contributed to planning and writing, and participated as an assessor in the study. All authors read and approved the final version of the manuscript.

\section{Acknowledgements}

The authors want to thank the Norwegian Ministry Of Health and Social Affairs for funding the study from July 1997 to December 1999, canalised through the National Insurance Administration (project no. 13345). This study could not have been performed without the support and contribution of the county and local National Insurance Offices in Troms.

\section{References}

I. Tellnes G, Brage S, Haland EM, Brodholt A: Hvilke symptomer og plager forer til sykmelding? ICPC-coding av pasientenes egne vurderinger $i$ allmennpraksis. [What symptoms and complaints result in sick-listing? ICPC-coding of patients' own opinion in general practice]. Tidsskr Nor Laegeforen 1992, I I 2:1985-1988.

2. Fleten N, Johnsen R, Skipenes $B \varnothing$ : Sykmeldte tror tiltak på arbeidsplassen kan redusere sykefravær [Sick-listed patients think job adjustments might reduce sick-leaves]. Tidsskr Nor Laegeforen 1999, I 1 9:3730-3734.

3. Pransky G, Katz JN, Benjamin K, Himmelstein J: Improving the physician role in evaluating work ability and managing disability: a survey of primary care practitioners. Disabil Rehabil 2002, 24:867-874.

4. Krause N, Dasunger LK, Neuhauser F: Modified work and return to work: a review of the literature. Journal of Occupational Rehabilitation 1998, 8(2): I I3-139.

5. Scheel IB, Hagen KB, Oxman AD: Active sick leave for patients with back pain: all the players onside, but still no action. Spine 2002, 27:654-659.

6. Berg JE, Tellnes G, Noreik K, Melsom H: Sykmelding II-ordningen. Fra prosjektet Evaluering av oppfolging av langtidssykmeldte. [The sick leave notification II system. From the project Evaluation of follow-up of long-term sick leave patients]. Tidsskr Nor Laegeforen 1990, I I 0: I 393-1397.

7. Andersson HW, Lippestad JW, Leonardsen A, Paulsen B: Doktoren og papirarbeidet: skjemabruk og attestskriving $i$ allmennpraksis. [In Norwegian]. Trondheim, SINTEF Unimed NIS. SINTEF-rapport STF78 A995 101999.

8. Englund L, Svardsudd K: Sick-listing habits among general practitioners in a Swedish county. Scand J Prim Health Care 2000, 18:8I-86.

9. Brage S, Bentsen BG, Bjerkedal T, Nygard JF, Tellnes G: ICPC as a standard classification in Norway. Fam Pract 1996, 13:391-396.

10. Altman GD: Practical statistics for medical research. London: Chapman and Hall; 1991:396-409.

II. Bland JM, Altman DG: Statistical methods for assessing agreement between two methods of clinical measurement. Lancet 1986, I:307-310.

12. Cicchetti DV, Feinstein AR: High agreement but low kappa: II. Resolving the paradoxes. J Clin Epidemiol 1990, 43:55I-558.

13. Fleiss JL: The Measurement of Interrater Agreement. In Statistical Methods for Rates and Proportions New York: John Wiley; 1981:212-236.

14. Aronsson G, Gustafsson K., Dallner M: Sick but yet at work. An empirical study of sickness presenteeism. J Epidemiol Community Health 2000, 54:502-509.

15. Strand $\mathrm{K}$, Wergeland $\mathrm{E}$, Bjerkedal $\mathrm{T}$ : Job adjustment as a means to reduce sickness absence during pregnancy. Scand J Work Environ Health 1997, 23:378-384. 
16. Vahtera J, Kivimaki M, Pentti J, Theorell T: Effect of change in the psychosocial work environment on sickness absence: a seven year follow up of initially healthy employees. J Epidemiol Community Health 2000, 54:484-493.

17. Ringdal PR, Haug K, Maeland JG: Forer systematisk vurdering av Sykmelding II-erklaeringer til lavere trygdeforbruk? [Does systematic evaluation of sickness certification II lead to less use of health insurance?]. Tidsskr Nor Laegeforen 2002, 122:157-160.

18. Larsen BA, Forde $\mathrm{OH}$, Tellnes $\mathrm{G}$ : Legens kontrollfunksjon ved sykmelding. [Physician's role in certification for sick leave]. Tidsskr Nor Laegeforen 1994, I | 4: | 442- I 444.

19. Lofvander M: Attitudes towards pain and return to work in young immigrants on long-term sick leave. Scand J Prim Health Care 1999, 17:164-169.

20. Niedhammer I, Bugel I, Goldberg M, Leclerc A, Gueguen A: Psychosocial factors at work and sickness absence in the Gazel cohort: a prospective study. Occup Environ Med I998, 55:735-74I.

21. Ekberg K, Wildhagen I: Long-term sickness absence due to musculoskeletal disorders: the necessary intervention of work conditions. Scand J Rehabil Med 1996, 28:39-47.

22. Reiso H, Nygard JF, Brage S, Gulbrandsen P, Tellnes G: Work ability assessed by patients and their GPs in new episodes of sickness certification. Fam Pract 2000, 17:139-144.

\section{Pre-publication history}

The pre-publication history for this paper can be accessed here:

http://www.biomedcentral.com/1471-2458/4/8/prepub

Publish with Bio Med Central and every scientist can read your work free of charge

"BioMed Central will be the most significant development for disseminating the results of biomedical research in our lifetime. "

Sir Paul Nurse, Cancer Research UK

Your research papers will be:

- available free of charge to the entire biomedical community

- peer reviewed and published immediately upon acceptance

- cited in PubMed and archived on PubMed Central

- yours - you keep the copyright 